\title{
Drug-related problems in hospitalized patients on polypharmacy: the influence of age and gender
}

\author{
Yvonne Koh' \\ Fatimah Bte Moideen \\ Kutty ${ }^{2}$ \\ Shu Chuen $\mathrm{Li}^{\prime}$ \\ 'Department of Pharmacy, National \\ University of Singapore, Republic of \\ Singapore; ${ }^{2}$ Alexandra Hospital, \\ Republic of Singapore
}

\begin{abstract}
Background: Drug-related problems (DRPs) have been shown to prevail in hospitalized patients, and polypharmacy and increasing age have been identified as two important risk factors.

Objective: We investigated the occurrence of DRPs and adverse drug reactions (ADRs) amongst hospitalized patients prescribed polypharmacy, and the association of advanced age and female gender.

Method: A retrospective cross-sectional study was performed in an acute-care hospital in Singapore. Only patients prescribed polypharmacy were included. Mann-Whitney test was used to test for significant difference between the age and gender of patients and their risk of acquiring DRPs. The relative risks of developing DRP and ADR for geriatric patients and female patients were estimated.

Results: Of 347 patients prescribed polypharmacy (43\% female and 58.2\% geriatrics), no statistical correlations were observed between age and gender with developing DRPs. An increased number of medications was associated with higher risk for patients with DRPs on admission $(p=0.001)$, but not for inpatients with DRPs $(p=0.119)$. Results from patients with ADRs showed that the relative risk (RR) of geriatrics prescribed polypharmacy and major polypharmacy (10 and more drugs) were 1.01 and 1.23, respectively. Female patients had a RR of 0.79 compared with male patients in developing ADRs.
\end{abstract}

Conclusion: Results showed that among patients with polypharmacy, age and gender may not be as important as number of drugs prescribed as predictors of experiencing a DRP. A similar trend was observed in the development of ADRs.

Keywords: polypharmacy, drug-related problems, adverse drug reactions, geriatrics

\section{Introduction}

Drug-related problems (DRPs), which include adverse drug reactions (ADRs), unnecessary drug therapy, inappropriate choice of drugs, and untreated conditions, have been shown to prevail in hospitalized patients, with a reported incidence rate as high as 25\% (Steel et al 1981; Stewart and Cooper 1994). Undeniably, many factors can contribute to the high prevalence rate, but polypharmacy and older age have often been identified as important risk factors (Nolan and O'Malley 1988; Montamat and Cusack 1992; Stewart and Cooper 1994).

Polypharmacy is defined as the use of multiple medications by a single patient and is commonly observed among geriatric patients (Stewart and Cooper 1994). The use of multiple medications has been shown to predispose patients to ADRs (Williamson and Chopin 1980; Inman 1985; Nolan and O'Malley 1988; Hoigné et al 1990; Chrischilles et al 1992), drug-drug interactions (McInnes and Brodie 1988; Beers and Ouslander 1989; Stewart and Cooper 1994), and medication noncompliance 
(Bergman and Wiholm 1981a; Ramsay and Tucker 1981; Gillum and Barsky 1984), particularly in the geriatric population.

Among the potential contributing factors of DRPs, the association between polypharmacy and the incidence of ADRs has been most widely studied and documented. Incidences of ADR have been consistently shown to increase in an exponential rather than a linear manner with the number of drugs taken (Hurwitz and Wade 1969; Morgan et al 1988; Nolan and O’Malley 1988; Cadieux 1989). For example, significantly more ADR-associated hospital admissions have been observed among patients prescribed four or more drugs than those receiving up to three drugs (11.1\% vs 3.6\%) (Bergman and Wiholm 1981b). In another study, it was reported that hospitalized patients who experienced an adverse reaction took twice as many drugs (12.5 vs 6.3 drugs) as patients without ADRs (Hurwitz and Wade 1969). Besides the undesirable clinical consequences for the patients, ADRs also pose a significant financial burden to the healthcare system (Beers et al 1992). In a US study performed in 1992-1994, the estimated cost of treating reported adverse drug events among inpatients was US\$1.5 million per year at a university-affiliated hospital (Schneider et al 1995). Another more recent French study conducted in 1996-1997 showed the annual cost of drug-related hospital admission to a university hospital as $€ 3.85$ million per year (Lagnaoui et al 2000). Thus, reducing the use of unnecessary medicines and avoiding polypharmacy would be beneficial in aiding the reduction of healthcare cost beyond the confines of reduction in drug costs alone.

Of the risk factors, advanced age has been associated with substantial increased risk of acquiring ADR (Gurwitz et al 1990). A sevenfold increase in occurrence of ADRs from $3 \%$ to $21 \%$ has been shown to occur between patients aged 20-30 years and 60-70 years (Hurwitz 1969). In addition, many studies have shown that a large number of emergency room visits and hospital admissions amongst older people could be attributed to iatrogenic syndromes associated with polypharmacy (Grymonpre et al 1988; Colt and Shapiro 1989; Scheneider et al 1992; Stuck et al 1994; Hanlon et al 1997). Hence, polypharmacy plus old age could be considered a potent combination for ADRs to take place. The high risk of developing ADRs in patients with both risk factors was demonstrated when $35 \%$ of a study population of 167 older patients prescribed polypharmacy (taking 5 or more drugs) experienced a confirmed adverse drug event over a one-year period (Hanlon et al 1997).
However, other researchers had argued that this propensity of older patients experiencing ADRs was not being well substantiated by epidemiological data (Hoigné et al 1990). Furthermore, the failure to control for important age-related covariates (eg, clinical status of the patient) had also been cited as a limitation to the interpretation of many study results (Gurwitz and Avorn 1991). Some researchers proposed that inappropriate medication in the elderly might pose a higher risk for acquiring ADR than advanced age as a sole risk factor (Lindley et al 1992). Up to now, the issue of whether inappropriate drug use or advanced age should be considered the more important risk factor for developing DRPs remains unresolved. The resolution of this issue is of great relevance to the practice of clinical medicine, as it would allow physicians and pharmacists to focus more attention on patients with the "true" risk factors.

Another interesting observation about the studies relating to DRPs is that there exists little data on comprehensive DRPs among hospitalized patients. So far, most studies published had addressed either the problem of drug-related admissions to hospitals (Bergman and Wiholm 1981a; Bero et al 1991; Hallas et al 1992; Prince et al 1992; Courtman and Stallings 1995; Fattinger et al 2000), or focused only on ADRs among hospitalized patients (Hurwitz and Wade 1969; Brennan et al 1991; Classen et al 1997). A more comprehensive study of DRPs in hospitalized patients would provide valuable insights for the healthcare professionals trying to reduce the incidence of DRPs.

Finally, another issue that is pertinent to healthcare delivery and risk management is the impact of the numerous studies of DRPs on clinical practice. As most of the studies were performed between 10 and 20 years ago, it is unclear whether the results and lessons learnt from these studies have any influence on changing clinical practices. An assessment of the current situation would assist the healthcare providers in optimising intervention strategies according to needs and available resources.

In the current study, we attempted to evaluate some of the aforementioned issues. As polypharmacy is associated with the increased occurrence of DRPs (Bergman and Wiholm 1981b; Nolan and O'Malley 1988; Hallas et al 1992; Lindley et al 1992; Green et al 2000), our main objectives were to investigate the occurrence of all DRPs (at admissions and while hospitalized) among hospitalized patients prescribed polypharmacy, and to evaluate the association of two risk factors, namely advanced age and female gender, with DRPs and ADRs in particular. 
Since advanced age has always been associated with higher incidence of DRPs (Hurwitz and Wade 1969; Williamson and Chopin 1980; McMillan et al 1986; Beijer and De Blaey 2002), we wanted to see if this trend could be confirmed or supported by our local data. Also, female patients, being generally lighter in weight and smaller in build than their male counterparts but usually receiving the same drug doses, had been demonstrated to be more prone to ADRs in some studies (Bergman and Wiholm 1981b; Veehof et al 1999; Fattinger et al 2000). This is most probably attributable to the exposure to higher dose per body weight for the females. We postulated that this trend would be more pronounced in our predominantly Asian female patients (who are generally even lighter in weight than Caucasian counterparts).

In addition to helping to resolve the abovementioned issues, the results from this study could provide baseline information quantifying the problem of DRPs among hospitalized patients receiving polypharmacy in Singapore, and contribute to the formulation and implementation of risk management strategies.

\section{Methods}

\section{Study population}

We conducted a retrospective, cross-sectional study in a 404bed acute-care hospital in Singapore. Inpatient case notes and medication records were used in our data collection. Subjects were included in the study if they were inpatients on the last two Thursdays of November and December 2000, and who satisfied the criteria of being prescribed polypharmacy (see definition below). Thursday was chosen to ensure that the patients admitted over the weekend would have had their admitting medications checked or altered by the attending physicians. This would capture most DRPs (both causing admissions and those occurring during hospitalization) among these patients.

\section{Definitions}

DRP was defined as an event or circumstance that involves a patient's drug treatment that actually, or potentially, interferes with the achievement of an optimal outcome (Hepler and Strand 1990).

For ADRs, we used the World Health Organization definition which specifies an adverse reaction as a reaction which is noxious and unintended, and which occurs at dosages normally used for prophylaxis, diagnosis, therapy of disease, or for the modification of physiological function (WHO 1972).

Polypharmacy was defined as the daily consumption of 5 or more medications. Different strengths of the same drug were counted as one item. However, formulations of the one drug requiring different routes of administration were regarded as separate items. Combination drug, that is a drug with more than one active ingredient in it, was regarded as a single item.

\section{Data collection}

Patient's age, gender, principal diagnosis, concomitant disease states, medical history, concurrent medications and dosage, and medications taken prior to admission were recorded. Other data collected included biochemistry and hematology results, microbiological culture and sensitivity tests, and plasma drug concentrations when these were available. Normal laboratory values for the hospital were used to determine the presence of abnormalities. Renal function was estimated from creatinine clearance (Cockcroft and Gault 1976). DRPs experienced by the patients on admission and during their inpatient stay, together with the suspected drugs were extracted from their medical records. To avoid inter-rater variation, the case notes and medication records of the patients were reviewed by one of the investigators (YK), and any need for confirmation of the decision was resolved with the other investigators.

\section{Classification of DRPs}

DRPs were defined as inappropriate treatments, potential drug interactions, inappropriate dosages, unsafe drugs for patients, and ADRs experienced by patients on admission and during their inpatient stay. ADRs that occurred during the same period were characterized based on the drugs and drug class involved, the manifestations of these ADRs, and the frequency of occurrence. Due to the retrospective nature of the study, ADRs and their potential causality drugs were extracted from patients' medical case notes with no further evaluation and determination into the ADR causality.

Based on the case notes, the patients' existing conditions were matched with their drug therapy. Appropriate doses of drugs, appropriate drug indications, possible drug interactions, and ADRs were based on drug monographs in the 42nd edition of the British National Formulary (BNF Joint Formulary Committee 2002).

The appropriateness of control was based on the physician's documentation of the patient's condition in the 
medical case notes, together with any available laboratory results. For any documentation of a poorly controlled medical condition, the medication records were reviewed thoroughly to determine if the poor control was drug related (ie, if the patient was receiving adequate and/or appropriate medication at that time). Inappropriately controlled conditions due to lack of medications, or lack of synergistic medications, would be classified as "additional therapy required", while a drug was prescribed for no obvious indication would be classified as "unnecessary drug therapy".

In assessing the appropriateness in the choice of drugs, Beer's explicit criteria (Beers 1997) were used to identify medications that were deemed unsuitable for use in elderly patients more than 65 years old.

\section{Statistical analysis}

Chi-square test was employed to test for significant difference between the age of patients, as well as the gender of patients and their risk of getting DRPs. Mann-Whitney test was used to test for significant difference between the number of medications taken and the risk of DRPs. In all comparisons, the level of significance was adopted as 0.05 .

The relative risks of developing ADR and DRP for geriatric patients and female patients were estimated from the prevalence of these events compared with non-geriatrics and male patients, respectively.

\section{Results}

\section{Characteristics of study population}

There were 640 inpatients during the study period. Data were collected for 347 patients (54.2\%) prescribed polypharmacy. Their age ranged from 16 to 97 years (mean

Table I Ten most commonly prescribed drugs

\begin{tabular}{lcc}
\hline Drug & $\begin{array}{c}\text { Number of } \\
\text { patients }^{\mathbf{a}}\end{array}$ & $\mathbf{( \% )}^{\mathrm{b}}$ \\
\hline Paracetamol & 116 & 33.4 \\
Senna & 105 & 30.3 \\
Lactulose & 103 & 29.7 \\
Sangobion & 70 & 20.2 \\
Aspirin & 67 & 19.3 \\
Isosorbide dinitrate & 55 & 15.9 \\
Potassium chloride & 51 & 14.7 \\
Amlodipine & 50 & 14.4 \\
Famotidine & 50 & 14.4 \\
Enalapril & 42 & 12.1 \\
\hline
\end{tabular}

a Those who are receiving the drug.

${ }^{b}$ The percentage of study population receiving the drug.
$65.9 \pm 17.7$ years). Of the subjects recruited, $43 \%$ were female. Geriatric patients (patients more than 65 years old) made up $58.2 \%$ of our study population.

\section{Medication profile}

The number of medications per patient ranged from 5 to 14 (mean $7.4 \pm 2.1$ ). Paracetamol was the most commonly used drug (33.4\%) followed by two laxatives, senna and lactulose (prescribed in $30.3 \%$ and $29.7 \%$, respectively). A total of 181 patients $(52.2 \%$ of our study population) were taking laxatives; of which, 13 patients $(3.7 \%)$ were on 3 laxatives and 80 patients $(23.1 \%)$ were on 2 laxatives simultaneously. The ten most commonly prescribed medicines are shown in Table 1.

\section{DRPs on admission}

There were 32 cases of DRPs which resulted in, or were coincidental with admission. They could be classified into 4 broad categories: requiring additional therapy $(31.3 \%)$, non-compliance (28.1\%), adverse drug reactions (25\%), and inappropriate dosing (dose too low 12.5\%, dose too high $3.1 \%)$.

For the 10 patients who required additional therapy, the existing medical conditions of nine may have been better controlled if synergistic drugs were added onto their current medication. The tenth patient was admitted as a result of syncope secondary to chronic anemia which was not treated with medication.

Of the noncompliant patients, one of them had poor inhaler technique resulting in the exacerbation of his asthma problem. The remaining 8 patients were not compliant with their medication regime. Details of the DRPs during admission are published elsewhere (see Koh et al 2003).

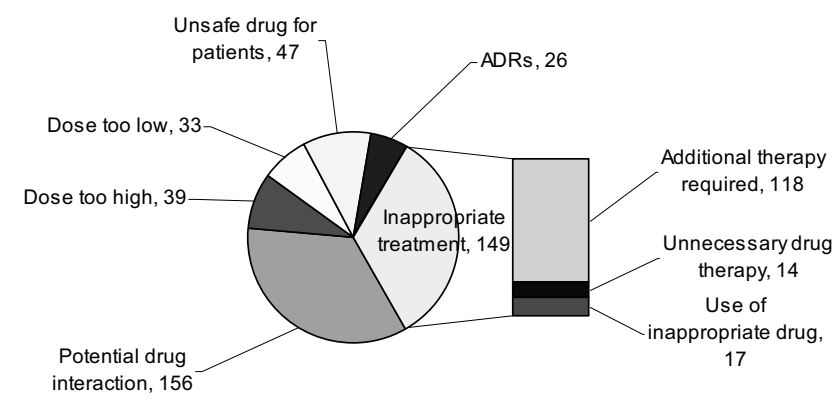

Figure I Drug-related problems and their number of incidences identified in patients during hospital stay. Abbreviation: ADRs, adverse drug reactions. 


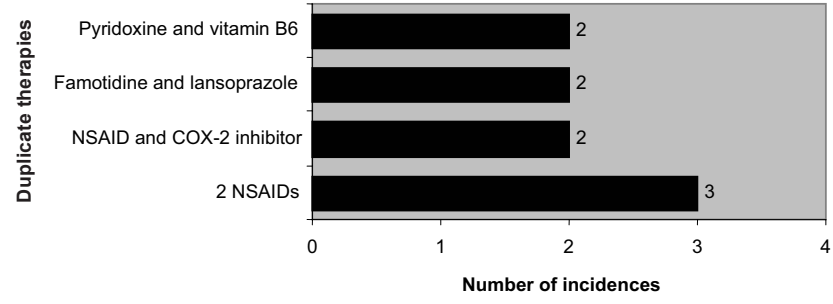

Figure 2 List of duplicate therapies. Abbreviation: NSAIDs, nonsteroidal antiinflammatory drugs.

\section{DRPs during hospital stay}

The types of DRPs identified during the study period included: (1) inappropriate treatment (comprises additional therapy, unnecessary drug therapy, and use of inappropriate drug); (2) potential drug interactions; (3) inappropriate dosages - dose too high or dose too low; (4) unsafe drug for patients; and (5) ADRs (Figure 1).

Of the 149 incidences of inappropriate treatment, 118 had an untreated condition that required additional therapy, with anemic patients (identified by their biochemistry results) making up $64.4 \%$ of this group. Another 9 patients would require additional drugs to improve the management of their existing medical conditions. For patients receiving unnecessary drug therapies, 5 had no recorded medical indication for their prescribed medications and the remaining patients were prescribed duplicate therapies (Figure 2). Patients taking drugs not recommended for their conditions made up the remaining 17 cases of inappropriate treatment. Of these, $82.4 \%$ was due to usage of a particular drug when contraindicated (eg, the use of propranolol in an asthmatic), and the rest was due to using a drug when the condition was already refractory to it (eg, using ciprofloxacin when culture and sensitivity results showed bacterial resistance) or when a particular drug was not even indicated for the condition (eg, prescribing paracetamol for giddiness).

For inappropriate dosages, the cases encountered were wrongly prescribed dosages, inappropriate administration frequencies, or the serum drug concentrations were higher

Table 2 Dose of medication too high for existing renal or hepatic function

\begin{tabular}{lrc}
\hline Drug & $\begin{array}{r}\text { Impaired } \\
\text { function }\end{array}$ & $\begin{array}{r}\text { Number } \\
\text { of patients }\end{array}$ \\
\hline Enalapril & Renal & 4 \\
Metronidazole & Hepatic & 2 \\
Allopurinol & Renal & $\mathrm{I}$ \\
Cefuroxime & Renal & $\mathrm{I}$ \\
Fluoxetine & Renal & $\mathrm{I}$ \\
Tolbutamide & Renal & $\mathrm{I}$ \\
Tramadol & Renal & $\mathrm{I}$ \\
\hline
\end{tabular}

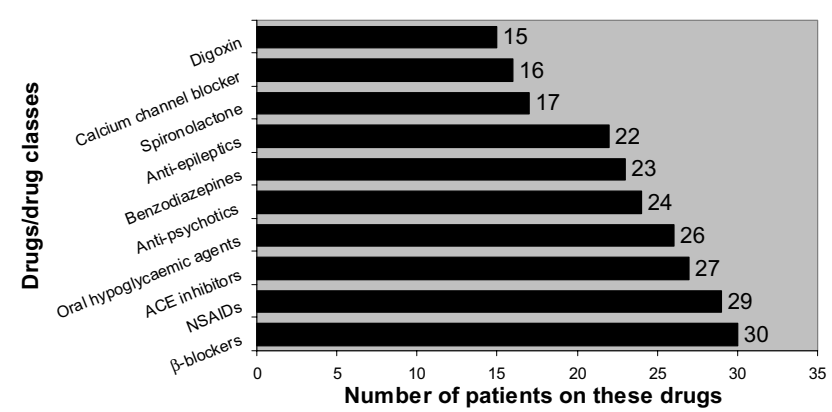

Figure 3 Ten drugs/drug classes that were most likely to be involved in causing drug-drug interactions.

or lower than recommended ranges during therapeutic drug monitoring. For some patients, the dosages of their medications were deemed as too high when we took into account their abnormal hepatic or renal function (Table 2).

Each combination of the drugs prescribed for the patients during their hospitalization were checked for potential interaction, and the top ten drugs/drug classes that were most likely to be involved in causing drug-drug interactions are listed in Figure 3. We only managed to identify cases of potential drug interactions during hospital stay as the documentation of drugs which the patients were on prior to admission was not comprehensive for all the patients.

The 47 cases of unsafe drug regimes during hospitalization were based on Beer's criteria, which identifies drugs unsuitable for use in patients more than 65 years old. Again, we could not identify unsafe drug usage for patients on admission due to limited documentation. Drug-pairs identified in our study that could give rise to potential severe interaction are shown in Table 3.

With regards to the analysis of risk factors, there were no statistical correlations when age and gender were compared between patients with and without DRPs, both on admission and during hospital stay. However, based on Mann-Whitney test, the number of medications prescribed for patients was not a risk factor for the presence of DRPs

Table 3 Significant potential drug interactions

\begin{tabular}{ll}
\hline Drug pair & Possible effects \\
\hline Atenolol + nifedipine & $\begin{array}{l}\text { Severe hypotension and heart failure } \\
\text { occasionally }\end{array}$ \\
Phenytoin + folic acid & $\begin{array}{l}\text { Decrease plasma level of phenytoin } \\
\text { Increase risk of myopathy }\end{array}$ \\
Simvastatin + erythromycin & Enhanced anticoagulant effect \\
Simvastatin + warfarin & Convulsion threshold lowered \\
Theophylline + calcium & \\
channel blocker & Possibly enhanced theophylline effect \\
\hline
\end{tabular}

Abbreviation: SSRI, selective serotonin reuptake inhibitor. 
Table 4 Identified cases of adverse drug reactions

\begin{tabular}{|c|c|c|c|}
\hline Drug class & Drugs & Manifestations of ADRs & Number of patients \\
\hline \multirow[t]{4}{*}{ NSAIDs } & Aspirin & Coffee ground vomitus & 4 \\
\hline & & Bleeding GIT & 2 \\
\hline & & Epigastric pain with vomiting & I \\
\hline & & Gastric ulcer & I \\
\hline \multirow[t]{3}{*}{ ACE inhibitor } & Enalapril & Declining renal function & I \\
\hline & & Chronic cough with wheezing & I \\
\hline & & Postural hypotension & I \\
\hline \multirow[t]{4}{*}{ Antiepileptics } & Carbamazepine & Hyponatremia & I \\
\hline & & Thrombocytopenia & I \\
\hline & Phenytoin & Giddiness & I \\
\hline & Valproate & Tremors & I \\
\hline \multirow[t]{4}{*}{ SSRIs } & Fluvoxamine & Hyponatremia & I \\
\hline & & Increased INR & I \\
\hline & & Increased liver function tests & I \\
\hline & Fluoxetine & Hyponatremia & I \\
\hline \multirow[t]{2}{*}{ Loop diuretic } & Frusemide & Dehydration & 2 \\
\hline & & Increased liver function tests & I \\
\hline Calcium channel blocker & Amlodipine & Postural hypotension & 2 \\
\hline \multirow[t]{2}{*}{ Antiplatelet } & Ticlopidine & Generalized rash & I \\
\hline & & Decreased hemoglobin & I \\
\hline Analgesic/antipyretic & Paracetamol & Itch & I \\
\hline Antiarrythmic & Procainamide & Antiphopholipid syndrome & I \\
\hline Antibiotic & Ethambutol & Generalized rash & I \\
\hline Antipsychotic & Sulpiride & Extrapyramidal side effects & I \\
\hline Beta-blocker & Propranolol & Asthma exacerbation & I \\
\hline Fibrinolytic & Streptokinase & Rigors and facial flushing & I \\
\hline Statins & Simvastatin & Increased liver function tests & I \\
\hline Sulfonylurea & Glipizide & Increased liver function tests & I \\
\hline
\end{tabular}

Abbreviations: ADRs, adverse drug reactions; NSAIDs, nonsteroidal antiinflammatory drugs; ACE, angiotensin converting enzyme; SSRIs, selective serotonin reuptake inhibitors; GIT, gastrointestinal tract; INR, international normalized ratio.

$(\mathrm{p}=0.119)$ during hospital stay, but it was a risk factor for patients with DRPs on admission $(p=0.001)$.

\section{ADR analysis}

There were 8 cases of identified ADRs on admission and 26 cases that occurred in 33 patients during hospital stay (one patient experienced two ADRs during the study period). Due to their small number of occurrence, we did an aggregated analysis of all the ADR cases (Table 4). Patients suspected of experiencing an ADR were taking a mean of $8.2( \pm 2.6)$ different medicines compared with those not having an ADR with a mean of $7.3( \pm 2.1)$ medicines $(p=0.015)$. Of those who experienced ADRs, 60.6\% were geriatrics. This formed about $10 \%$ of the geriatric patients in our study, and $36.4 \%$ of these geriatric patients were female.

Based on the results, the relative risk for geriatrics above 65 years in our study to develop ADRs was $1.01(95 \%$ confidence interval (CI): $0.52,1.85)$, and the relative risk for female patients in developing ADRs was 0.79
(95\% CI: 0.40, 1.55). However, when we did the same analysis for patients on major polypharmacy (10 or more drugs) the relative risks for geriatrics and female patients developing ADRs were 1.23 (95\% CI: 0.36, 4.25) and 0.66 (95\% CI: $0.21,2.02)$, respectively.

The prevalence rates of developing DRPs and ADRs for the various patient subgroups during the study period are summarized in Table 5.

\section{Discussion}

Polypharmacy is a ubiquitous problem plaguing nearly all healthcare systems. Here, we investigated the occurrence of not only ADRs, but all DRPs on admission and during hospitalization among patients receiving polypharmacy. An evaluation of the status and possibly the risk factors involved in DRPs would give us some basic information for working towards improving the current situation.

From our results, nearly $10 \%$ of our study population had at least one DRP at admission. However, this might be an underestimate due to the lack of comprehensive 
Table 5 Prevalence rates of developing DRPs and ADRs for the various patient subgroups

\begin{tabular}{|c|c|c|c|c|c|c|}
\hline \multirow[b]{4}{*}{ Patients } & \multicolumn{6}{|c|}{ Prevalence rate } \\
\hline & \multirow{2}{*}{\multicolumn{2}{|c|}{ Polypharmacy }} & \multirow{2}{*}{\multicolumn{2}{|c|}{$\begin{array}{r}\text { Minor } \\
\text { polypharmacy }\end{array}$}} & \multirow{2}{*}{\multicolumn{2}{|c|}{$\begin{array}{r}\text { Major } \\
\text { polypharmacy }\end{array}$}} \\
\hline & & & & & & \\
\hline & $\%$ & $(n / N)^{a}$ & $\%$ & $(\mathrm{n} / \mathrm{N})^{\mathrm{a}}$ & $\%$ & $(\mathrm{n} / \mathrm{N})^{\mathrm{a}}$ \\
\hline \multicolumn{7}{|l|}{$D R P$} \\
\hline All study patients & 72.0 & $250 / 347$ & 70.2 & $203 / 289$ & 81.0 & $47 / 58$ \\
\hline Less than 65 years old with DRP & 72.9 & $102 / 140$ & 74.2 & $89 / 120$ & 65.0 & $13 / 20$ \\
\hline 65-74 years old with DRP & 71.6 & $53 / 74$ & 67.3 & $37 / 55$ & 84.2 & $16 / 19$ \\
\hline 7-84 years old with DRP & 69.0 & $58 / 84$ & 64.3 & $45 / 70$ & 92.9 & $13 / 14$ \\
\hline 85 years old and above with DRP & 75.5 & $37 / 49$ & 72.7 & $32 / 44$ & 100 & $5 / 5$ \\
\hline Female patients with DRP & 41.2 & $103 / 250$ & 37.4 & $76 / 203$ & 57.4 & $27 / 47$ \\
\hline Male patients with DRP & 58.8 & $147 / 250$ & 62.6 & $127 / 203$ & 42.6 & $20 / 47$ \\
\hline \multicolumn{7}{|l|}{$A D R$} \\
\hline All study patients & 9.5 & $33 / 347$ & 9.3 & $27 / 289$ & 10.3 & $6 / 58$ \\
\hline Less than 65 years old with ADR & 15.7 & $22 / 140$ & 16.7 & $20 / 120$ & 10.0 & $2 / 20$ \\
\hline 65-74 years old with ADR & 0 & $0 / 74$ & 0 & $0 / 55$ & 0 & $0 / 19$ \\
\hline $75-84$ years old with ADR & 6.0 & $5 / 84$ & 2.9 & $2 / 70$ & 21.4 & $3 / 14$ \\
\hline 85 years old and above with ADR & 12.2 & $6 / 49$ & 11.4 & $5 / 44$ & 20.0 & $1 / 5$ \\
\hline Female patients with ADR & 27.3 & $9 / 33$ & 29.6 & $8 / 27$ & 16.7 & $1 / 6$ \\
\hline Male patients with ADR & 72.7 & $24 / 33$ & 70.4 & $19 / 27$ & 83.3 & $5 / 6$ \\
\hline
\end{tabular}

${ }^{a} \mathrm{n}$ denotes number of patients experiencing the event, and $\mathrm{N}$ denotes the total number of subjects in the particular category.

Abbreviations: DRPs, drug-related problems; ADRs, adverse drug reactions.

documentation at the point of admission. Comparatively, $63.4 \%$ of our study population (ie, approximately 3 out of 5 patients) had at least one DRP, albeit theoretical or actual, during their hospitalization. However, there was no equivalent comparison found in the published literature since we recruited only patients who were prescribed polypharmacy. Nevertheless, the high percentage of patients developing DRP here does highlight the need for more attention to the group of patients prescribed polypharmacy.

Although we separated those DRPs present on admission and those discovered while hospitalized, they will be discussed as a whole with emphasis on potential drug-drug interaction, appropriate dosages, and ADRs, as these DRPs might have been preventable if proper checks were carried out by physicians and pharmacists.

Our analysis on DRPs showed that potential drug-drug interactions accounted for a substantial amount of potential drug toxicity $(34.8 \%)$. Numerous drug combinations that resulted in modification of pharmacological action or in drug toxicity have been documented (D'Arcy and Griffen 1986). In the present study, $59 \%$ of possible drug-drug interaction occurred in geriatric patients. The drugs most implicated were $\beta$-blockers (namely, atenolol and propranolol), nonsteroidal antiinflammatory agents (NSAIDs) (including aspirin, ketoprofen, diclofenac, and mefenamic acid), and angiotensin converting enzyme (ACE) inhibitors. This is consistent with published data citing that the average number of drug-drug interactions involving anticoagulants and antihypertensives were significantly higher than other drug groups (May et al 1977).

In addition, we also identified drug-pairs in our study that could give rise to potential severe interaction (Table 3 ). We acknowledge that the judgment here is based on theoretical consideration. In clinical practice, some of these combinations may still be used, but the patient will need to be closely monitored for manifestations such as lack of therapeutic efficacy or toxicity, especially for drugs whose therapeutic effects may be diminished or augmented when used in those combinations. As drug interactions can affect patient's clinical outcome, quality of life, as well as contribute to unnecessary healthcare cost, the high prevalence rate $(\sim 30 \%)$ in this study would make this an important area requiring further investigation. As the study was carried out prior to the introduction of clinical pharmacy services at the study hospital, future pharmacists should focus on reviewing patients' medication charts and checking for potential drug interactions.

Another common aspect of DRPs is inappropriate dosages of medicines. Medication dosages were not adjusted for 11 patients with either renal or hepatic impairment. This made up $15.3 \%$ of all the patients receiving inappropriate drug dosages, and $2.4 \%$ of the entire DRPs in this study. Again, this might be an underestimate as the documentation in the patient's case notes was not very comprehensive and 
our judgment was based on available biochemistry reports. Moreover, there might be further cases of renal and hepatic impairment that were missed during analysis. With proper monitoring, it is possible to substantially reduce such incidences.

ADR is another important subset of DRPs. Nearly $10 \%$ of inpatients were found to have an ADR, which is higher than the ADR incidence of $6.7 \%$ found in the meta-analysis of 39 prospective studies from US hospitals (Lazarou et al 1998). However, it was in line with the report from another study showing $10 \%-20 \%$ of hospitalized patients experiencing at least one ADR during their hospital stay (Brennan et al 1991). Since our study was carried out only on patients prescribed polypharmacy, the only inference that could be drawn was that the ADR incidence was probably comparable to international figures.

In evaluating the drugs frequently implicated in ADRs (Table 4), NSAIDs and ACE inhibitors were ranked the highest, closely followed by antiepileptics and serotoninselective reuptake inhibitors (SSRIs). The drugs implicated in the present study are again similar to what has been reported (Courtman and Stallings 1995; Green et al 2000). This congruency highlights that there is a rationale to focus more attention on patients prescribed certain drugs or drug classes.

In the attempt to identify risk factors, our results supported published findings that the number of drugs taken by a patient is an important risk factor for ADRs. Definitely, the use of polypharmacy in patients is sometimes necessary to control or manage medical conditions. However, a patient may often be taking a multitude of medications because medications were used as substitutes for careful diagnostic maneuvres or effective nonpharmacologic therapies (Gurwitz et al 1990). Therefore, before prescribing a medication, it is important to determine if the patient's condition is caused by a current medication. It defeats the purpose if additional agents are prescribed to deal with the symptoms of adverse drug effects and this in turn potentiates the problem of polypharmacy.

The study also attempted to estimate the relative risk of developing ADRs using the age and gender of patients as risk factors. So far, we know of only one study that determined the relative risk of age (as a risk factor) in developing ADR in patients on major polypharmacy (see McMillan et al 1986). The establishment and knowledge of the relative importance of various risk indicators would lead to better risk management strategy among different patient subgroups.
From our analysis for patients already receiving polypharmacy, we found that geriatrics had a similar risk in experiencing an ADR compared with non-geriatrics. However, this relative risk was increased to 1.23 if we included only patients who were on major polypharmacy (10 drugs or more). Although we did not manage to see any statistically significant correlation between increasing age and increased likelihood of developing ADR, this could be due to our small sample size.

Likewise, where gender comparison is concerned, our results showed that female patients did not have a higher risk in developing ADRs when compared with male patients. This finding is contrary to those reported from Denmark (Hallas et al 1992) and the Netherlands (Veehof et al 1999) where the relative risk in developing ADRs for female patients was 1.57 (95\% CI: 1.15, 2.14) and 1.46 (95\% CI: $1.09,1.75)$, respectively. However, there were some differences in patient characteristics between the studies. In the Danish study, a total of 1999 patients of all ages, regardless of whether they were receiving polypharmacy or not were recruited (Hallas et al 1992). For the Dutch study, 2185 geriatric patients (65 years and older) prescribed polypharmacy were recruited, and polypharmacy was defined as long-term use of 2 or more drugs. In comparison, our inclusion criteria for polypharmacy, defined as 5 or more drugs, had restricted the number of eligible patients during the study period. The much bigger sample sizes in the previous two studies allowed them to be more sensitive in detecting the correlation between female gender and the risk of developing ADRs.

\section{Conclusions}

In summary, several observations could be drawn from the study results.

1. Our results established that the situation of drug therapy related problems in hospitalized patients receiving polypharmacy in Singapore is comparable to that occurring in other developed countries. One important interpretation of this would be that although DRPs have been studied and reported for the past twenty years, lessons and experiences from these studies have not exactly been translated into effective management of these problems. Further investigations are required to see what the underlying problem is in the current healthcare operating system that is causing this failure.

2. Regarding risk factors, our results showed that among patients with polypharmacy, age and gender may not be as important as the number of drugs prescribed as 
predictors of experiencing a DRP. In our case, neither older nor female patients showed a higher risk of developing DRPs, but this may be confounded by our inclusion criteria. A similar trend was observed in the developing of ADRs.

3. We also showed that the drugs causing DRPs in this study are similar to those in overseas studies. Through identifying drugs that are most likely to cause DRPs, healthcare professionals could spend more time monitoring patients prescribed these drugs.

Based on these findings, we would advocate applying the $20 / 80$ principle in business management into clinical risk management here. By identifying and properly managing the small percentage of high-risk patients (such as those with risk factors for developing DRPs and those prescribed drugs commonly associated with DRPs), we would be able to minimize or prevent most of these DRPs. We believe that with such an approach, the rampaging problem of DRPs can be at least dampened.

\section{References}

Beers MH. 1997. Explicit criteria for determining potentially inappropriate medication use by the elderly. Arch Intern Med, 157:1531-6.

Beers MH, Ouslander JG. 1989. Risk factors in geriatric drug prescribing. A practical guide to avoiding problems. Drugs, 37:105-12.

Beers MH, Ouslander JG, Fingold SF, et al. 1992. Inappropriate medication prescribing in skilled-nursing facilities. Ann Intern Med, 117:684-9.

Beijer HJM, De Blaey CJ. 2002. Hospitalisations caused by adverse drug reactions (ADR): a meta-analysis of observational studies. Pharm World Sci, 24:46-54.

Bergman U, Wiholm BE. 1981a. Drug-related problems causing admission to a medical clinic. Eur J Clin Pharmacol, 20:193-200.

Bergman U, Wiholm BE. 1981b. Patient medication on admission to a medical clinic. Eur J Clin Pharmacol, 20:185-91.

Bero LA, Lipton HL, Bird JA. 1991. Characterization of geriatric drugrelated hospital readmissions. Med Care, 29:989-1003.

BNF Joint Formulary Committee. 2002. British National Formulary. London: British Medical Association and Royal Pharmaceutical Society of Great Britain.

Brennan TA, Leape LL, Laird NM, et al. 1991. Incidence of adverse drug events and negligence in hospitalized patients: results of Harvard Medical Practice Study I. N Engl J Med, 324:370-6.

Cadieux RJ. 1989. Drug interactions in the elderly. How multiple drug use increases risk exponentially. Postgrad Med, 86:179-86.

Chrischilles EA, Segar ET, Wallace RB. 1992. Self-reported adverse drug reactions and related resource use. Ann Intern Med, 117:634-40

Classen DC, Pestotnik SL, Evans RS, et al. 1997. Adverse drug events in hospitalized patients. Excess length of stay, extra costs, and attributable mortality. JAMA, 277:301-6.

Cockcroft DW, Gault MH. 1976. Prediction of creatinine clearance from serum creatinine. Nephron, 16:31-41.

Colt HG, Shapiro AP. 1989. Drug induced illness as a cause for admission to a community hospital. J Am Geriatr Soc, 37:323-6.

Courtman BJ, Stallings SB. 1995. Characterisation of drug-related problems in elderly patients on admission to a medical ward. Can J Hosp Pharm, 48:161-6.

D’Arcy PF, Griffen JP. 1986. Iatrogenic diseases. Oxford: Oxford Univ Pr.
Fattinger K, Roos M, Vergères P, et al. 2000. Epidemiology of drug exposure and adverse drug reactions in two Swiss departments of internal medicine. Br J Clin Pharmacol, 49:158-67.

Gillum RF, Barsky AJ. 1984. Diagnosis and management of patient noncompliance. JAMA, 228:1563-7.

Green CF, Mottram DR, Rowe PH, et al. 2000. Adverse drug reactions as a cause of admission to an acute medical assessment unit: a pilot study. J Clin Pharm Therap, 25:355-61.

Grymonpre RE, Mitenko PA, Sitar DS, et al. 1988. Drug associated hospital admissions in older medical patients. J Am Geriatr Soc, 36:1092-8.

Gurwitz JH, Avorn J. 1991. The ambiguous relation between aging and adverse drug reactions. A Intern Med, 114:956-66.

Gurwitz JH, Soumerai SB, Avorn J. 1990. Improving medications prescribing and utilization in the nursing home. $J$ Am Geriatr Soc, $38: 542-52$.

Hallas J, Gram LF, Grodum E, et al. 1992. Drug related admissions to medical wards: a population based survey. Br J Clin Pharmacol, 33 : $61-8$.

Hanlon JT, Schmader KE, Koronkowski MJ, et al. 1997. Adverse drug events in high risk older outpatients. J Am Geriatr Soc, 45:945-8.

Hepler CD, Strand LM. 1990. Opportunities and responsibilities in pharmaceutical care. Am J Hosp Pharm, 47:533-43.

Hoigné R, Lawson DH, Weber E. 1990. Risk factors for adverse drug reactions - epidemiological approaches. Eur J Clin Pharmacol, 39:321-5.

Hurwitz N. 1969. Predisposing factors in adverse reactions to drugs. $B M J$, 1:536-9.

Hurwitz N, Wade OL. 1969. Intensive hospital monitoring of adverse reactions to drugs. $B M J, 1: 531-6$.

Inman WH. 1985. Under-reporting of adverse drug reactions. $B M J$, 290:1355.

Koh Y, Fatimah MK, Li SC. 2003. Therapy related hospital admission in patients on polypharmacy in Singapore: a pilot study. Pharm World Sci, 25:135-7.

Lagnaoui R, Moore N, Fach J, et al. 2000. Adverse drug reactions in a department of systemic diseases-oriented internal medicine: prevalence, incidence, direct costs and avoidability. Eur J Clin Pharmacol, 56:181-6.

Lazarou J, Pomeranz BH, Corey PN. 1998. Incidence of adverse drug reactions in hospitalized patients: a meta-analysis of propective studies. JAMA, 279:1200-5.

Lindley CM, Tully MP, Paramsothy V, et al. 1992. Inappropriate medication is a major cause of adverse drug reactions in elderly patients. Age Ageing, 21:294-300.

May FE, Stewart RB, Cluff LE. 1977. Drug interactions and multiple drug administration. Clin Pharmacol Therap, 22:322-8.

McInnes GT, Brodie MJ. 1988. Drug interactions that matter. A critical reappraisal. Drugs, 36:83-110.

McMillan DA, Harrison PM, Rogers LJ, et al. 1986. Polypharmacy in an Australian teaching hospital. Preliminary analysis of prevalence, types of drugs and associations. Med J Aust, 145:339-42.

Montamat SC, Cusack B. 1992. Overcoming problems with polypharmacy and drug misuse in the elderly. Clin Geriatr Med, 8:143-58.

Morgan K, Adllosso H, Ebrahim S, et al. 1988. Prevalence, frequency and duration of hypnotic drug use among the elderly living at home. $B M J$, 296:601-2.

Nolan L, O’Malley K. 1988. Prescribing for the elderly: part 1. Sensitivity of the elderly to adverse drug reactions. J Am Geriatr Soc, 36:142-9.

Prince BS, Goetz CM, Rihn TL, et al. 1992. Drug-related emergency department visits and hospital admissions. Am J Hosp Pharm, 49:1696-700.

Ramsay LE, Tucker GT. 1981. Clinical pharmacology. Drugs and the elderly. BMJ, 282:125-7.

Scheneider JK, Mion LC, Frengley JD. 1992. Adverse drug reactions in an elderly outpatient population. Am J Hosp Pharm, 49:90-6.

Schneider PJ, Gift MG, Lee YP, et al. 1995. Cost of medication-related problems at a university hospital. Am J Health-System Pharm, $52: 2415-18$ 
Steel K, Gertman PM, Crescenzi C, et al. 1981. Iatrogenic illness on a general medical service at a university hospital. $N$ Engl $J$ Med, 304:638-42.

Stewart RB, Cooper JW. 1994. Polypharmacy in the aged. Practical solutions. Drugs Aging, 4:449-61.

Stuck AE, Beers MH, Steiner A, et al. 1994. Inappropriate medication use in community-residing older persons. Arch Intern Med, 154: 2195-200.
Veehof LJG, Stewart RE, Meyboom-de Jong B, et al. 1999. Adverse drug reactions and polypharmacy in the elderly in general practice. Eur $J$ Clin Pharmacol, 55:533-6.

Williamson J, Chopin JM. 1980. Adverse reactions to prescribed drugs in the elderly: a multicentre investigation. Age Ageing, 9:73-80.

[WHO] World Health Organization International Drug Monitoring. 1972. The role of national centres. Technical report series 498 . Geneva: WHO. 